\title{
Absorbable synthetic versus catgut suture material for episiotomy repair
}

\author{
Shashikala H. Gowda, Rakshitha B.*
}

Department of Obstetrics and Gynecology, Kempegowda Institute of Medical Sciences, Bangalore, Karnataka, India

Received: 28 June 2021

Revised: 29 July 2021

Accepted: 30 July 2021

\section{*Correspondence:}

Dr. Rakshitha B.,

E-mail: rakshirakshitha0@gmail.com

Copyright: ( $)$ the author(s), publisher and licensee Medip Academy. This is an open-access article distributed under the terms of the Creative Commons Attribution Non-Commercial License, which permits unrestricted non-commercial use, distribution, and reproduction in any medium, provided the original work is properly cited.

\section{ABSTRACT}

Background: Episiotomy is a planned surgical incision made in perineum during childbirth. The type of suture material used for perineal repair following episiotomy will have effect on the intensiy of the pain experienced by mother. The objective of the present study is to determine the effects of rapide vicryl and catgut suture material on the amount of short term pain experienced by mother and to assess the amount of analgesia used following episiotomy suturing.

Methods: Women with episiotomy cut was divided into two groups: group A consisted of episiotomy repair with catgut and group B with rapide vicryl. Following episiotomy pain will be assessed by visual analogue scale.

Results: In KIMS hospital Bangalore - there was significant reduction in short term pain by vicryl rapide compared to chromic catgut and the need for analgesia.

Conclusions: Vicryl rapide is effective in reducing the morbidity associated with episiotomy repair. There was significant reduction in short term pain and the need for analgesia, with decrease incidence of wound dehiscence.

Keywords: Episiotomy, Chromic catgut, Vicryl rapide

\section{INTRODUCTION}

Episiotomy is a surgical cut made in perineum during childbirth. Episiotomy was introduced in the 18th century without having strong scientific evidence of its benefits. Its use was justified for prevention of severe perineal tears, better future sexual function and a reduction in urinary and fecal incontinence. It facilitated child birth but created challenging anatomical reconstruction. However no data support long term benefits of a routine episiotomy in obstetric practice. ${ }^{1}$

It is one of the most commonly performed procedures on women worldwide. Initially described in 1742, episiotomy was introduced into the United States in the mid-19th century. ${ }^{2}$ In 1920 , at a meeting of the American gynaecological society in Chicago, Dr. Joseph DeLee first publicly advocated the routine adoption of mediolateral episiotomy for all deliveries in nulliparous women. ${ }^{3}$

The type of suture material used for perineal repair following episiotomy will have effect on the intensity of pain experienced by mother.

Catgut is manufactured from collagen derived from healthy mammals (serosal and submucosal layer of small intestine of cattle, sheep and goat) and hence causes inflammatory response in the tissue. It is a type of suture material that is naturally degraded by body's own proteolytic enzymes. Absorption is completed by 90days and full tensile strength remains for at least 7 days.

Rapide vicryl are synthetic material and reported to cause less tissue reaction. Composed of $90 \%$ glycolide and $10 \%$ of L-lactide copolymer. Original tensile strength is lost 
between 4-5 weeks and absorption is completed between 56-70 days.

\section{METHODS}

The study was a prospective comparative randomized study. The study was conducted at the department of OBG, Kempegowda Institute of Medical Sciences, Bangalore. The duration of the study was from December 2020-March 2021.

\section{Source of study}

The study will be conducted in department of obstetrics and gynaecology in KIMS hospital and research centre on women following episiotomy repair

A total 60 women will be divided into 2 groups of 30 each into group A and group B. Group A included suturing with catgut and group B included suturing with rapide vicryl.

\section{Inclusion criteria}

All primiparous and multiparous women who have sustained perineal trauma and requiring stitching following an instrumental or spontaneous vaginal delivery were included.

\section{Exclusion criteria}

Patients following epidural analgesia were excluded from the study.

\section{Methodology}

Women following vaginal delivery with episiotomy cut will be divided into two groups: group A included episiotomy repair with catgut and group B included episiotomy repair with rapide vicryl.

In all women included in study, brief history is taken about known allergies, past medical and surgical history. Following episiotomy, pain will be assessed by visual analogue scale.

\section{Ethical clearance}

Ethical clearance was taken from the institutional ethics committee.

\section{Statistical analysis}

The study data will be analyzed using statistical package for social sciences (SPSS). Independent Chi square test will be used to correlate different methods of diabetes screening.

\section{RESULTS}

Out of 60 patients- 2 members $(3.33 \%)$ belonged to age group of 18-20 years, among that 1 were present in each group A and B. 24 members (40\%) belonged to age group of 21-25 years, among that 14 were in group A and 10 were in group B. 30 members $(50 \%)$ belonged to age group of 26-30 years, among that 13 were in group A and 17 were in group B. 4 members $(6.66 \%)$ belonged to age group of 31-35 years, among that 1 were in group A and 3 were in group B (Table 1).

Out of 60 patients, 32 members (53.3\%) were primigravida, among that 17 were in group $\mathrm{A}$ and 15 were in group B and 28 members $(46.6 \%)$ were multigravida, among that 15 were in group A and 13 were in group B (Table 2).

Table 1: Age group distribution among pregnant women.

\begin{tabular}{|lllll|}
\hline Age (years) & Total number of pregnant women & Percentage (\%) & Group A & Group B \\
\hline $\mathbf{1 8}-\mathbf{2 0}$ & 02 & 3.33 & 01 & 01 \\
\hline $\mathbf{2 1}-\mathbf{2 5}$ & 24 & 40.0 & 14 & 10 \\
\hline $\mathbf{2 6}-\mathbf{3 0}$ & 30 & 50.0 & 13 & 17 \\
\hline $\mathbf{3 1 - 3 5}$ & 04 & 6.66 & 01 & 03 \\
\hline
\end{tabular}

Table 2: Distribution of parity among each group.

\begin{tabular}{|lllll|}
\hline Parity & Total number & Total percentage (\%) & Group A & Group B \\
\hline Primigravida & 32 & 53.3 & 17 & 15 \\
\hline Multigravida & 28 & 46.6 & 15 & 13 \\
\hline
\end{tabular}

On day 0,24 patients $(80 \%)$ out of 30 of group A had severe pain compared to 4 patients $(13.3 \%)$ out of 30 of group B. On day 1, 20 patients $(66.6 \%)$ out of 30 of group $\mathrm{A}$ had severe pain compared to 4 patients $(13.3 \%)$ out of 30 of group B. On day 2, 15 patients $(50 \%)$ out of 30 of group A had severe pain compared to 2 patients $(6.6 \%)$ out of 30 of group B. On day 3, 9 patients (30\%) out of 30 of group A had severe pain compared to 1 patient (3.33\%) out of 30 of group B (Figure 1). On day 7, among the 15 patients, who had mild pain, 14 members $(93.3 \%)$ belong 
to chromic catgut group and 1 member $(6.66 \%)$ belong to vicryl rapide. On day 15, among the 7 patients, who had mild pain, 7 members $(100 \%)$ belong to chromic catgut group.

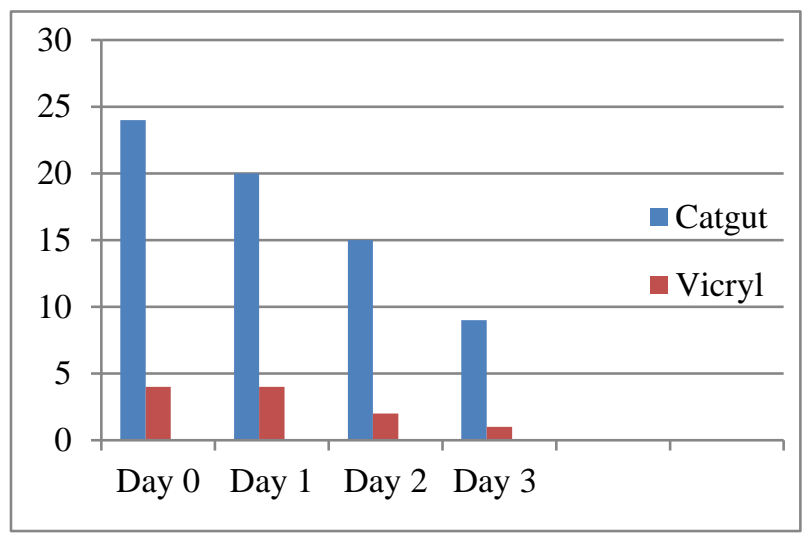

Figure 1: Depicting severe pain experienced by patients.

There was significant reduction in need for analgesia. On day 0 , all patients of group $A$ and group $B$ required analgesia for pain relief. On day 1 , out of 14 patients had no pain, of which 2 patients $(14.28 \%)$ belong to group A and 12 patients $(85.7 \%)$ belong to group B. On day 2, out of 36 patients had no pain, of which 10 patients $(27.7 \%)$ belong to group A and 26 patients $(72.2 \%)$ belong to group B. On day 3, out of 39 patients had no pain, of which 12 patients $(30.76 \%)$ belong to group $\mathrm{A}$ and 27 patients $(69.23 \%)$ belong to group B (Figure 2 ).

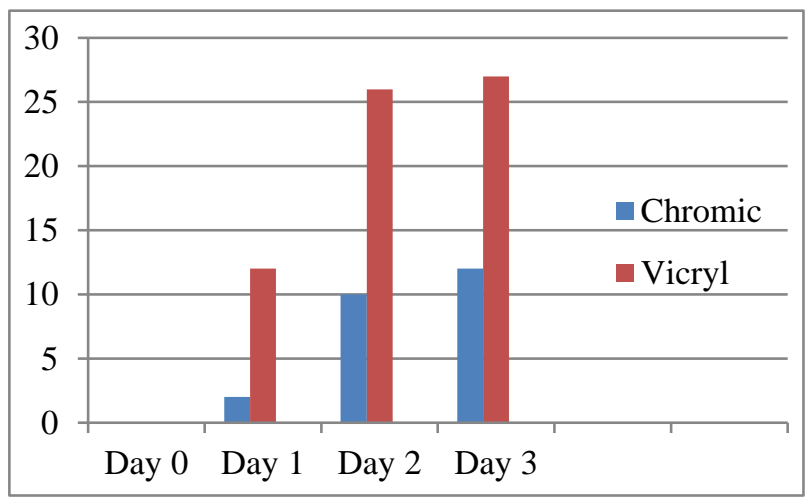

Figure 2: Depicting number of patients not requiring analgesia.

\section{DISCUSSION}

Because of the high frequency of pain and suffering experienced by women following vaginal birth, even a small improvement would be significant.

In our present study, there was significant difference in pain perception at day 2 postpartum. Analgesic was given to all the subjects. Only $13.3 \%$ of the group B experienced severe pain, compared to $50 \%$ of the control group. On the $15^{\text {th }}$ day, among 7 members who had no pain, none of the women in the polyglactin group complained of pain, compared to 7 members of the chromic catgut group who experienced mild pain, which was statistically significant. This is similar to the study conducted in 150 patients by Joseph et al in 2008.

Masson et al studied the repair of 2000 episiotomies with polyglactin 910 (vicryl rapide). There was statistically significant difference in the short term pain perception.

Table 3: Pain perception.

\begin{tabular}{|llll|}
\hline Total & No pain & Bearable pain & $\begin{array}{l}\text { Unbearable } \\
\text { pain }\end{array}$ \\
\hline $\mathbf{2 0 0 0}$ & 1979 & 20 & 1 \\
\hline
\end{tabular}

Masson et al used a continuous approach on all planes to examine the usage of fast-absorbing polyglactin (vicryl rapide) in a cohort of 2000 patients. On the sixth day, all sutures were in place because to vicryl rapide's outstanding tissue compatibility. On day 6,99 percent of the patients were pain-free. ${ }^{4}$

In 192 patients, Leroux and Bujold examined the effects of chromic catgut, polyglactin, and fast-absorbing polyglactin for perineal repair on short-term pain and sexual intercourse. The need for analgesics was greatly reduced with fast-absorbing polyglactin compared to normal polyglactin. At 6 weeks, resumption of pain-free sexual intercourse was more common. ${ }^{5}$

In a study of 1361 people, Greenburg et al compared the healing properties of chromic catgut to fast-absorbing polyglactin. At 48 hours, participants in the fast-absorbing polyglactin group had a substantial reduction in discomfort (25 percent versus 34 percent; $\mathrm{p}=0.006$ ). In the fastabsorbing polyglactin subject, there was a substantial reduction in analgesic use ( 5 percent versus $10 \% ; \mathrm{p}=0.048$ ) at 10 to 14 days. $^{6}$

For perineal repair, Kettle and Johanson evaluated eight studies that included absorbable synthetic suture with plain or chromic catgut suture. Absorbable synthetic suture material appears to reduce women's short-term pain, according to the findings (odds ratio 0.62, 95 percent confidence interval 0.54 to 0.71$)^{7}$

Shah et al proposed that vicryl rapide sutures used for perinealrepair results in less short term pain compared to chromic catgut. ${ }^{8}$

Guideline no. 23 of the royal college of obstetricians and gynecologists showed that the absorbable synthetic material for repair of perineal trauma is associated with less short term pain. ${ }^{9}$

Vicryl and vicryl rapide were compared by McElhinney et al. In terms of pain perception, there was no difference between the two groups after 24 hours and day 3 . However, at 6 weeks, the vicryl group had a significantly 
higher rate of dyspareunia. Joseph et al studied the short term and long term effects of episiotomy repair with absorbable synthetic versus chromic catgut suture material. The study was conducted in a tertiary care railway hospital on 150 patients. It was a prospective, comparative study between polyglactin (vicryl rapide) 2-0 versus polyglactin (vicryl) 1-0 versus chromic catgut 1-0. Polyglactin (vicryl rapide) group was found to be associated with less pain and lesser need for analgesic $(\mathrm{p}<0.05)$, than chromic catgut and standard polyglactin group. Removal of residual suture material was more common with standard polyglactin. ${ }^{10}$

In the Ipswich infant birth research, Grants et al followed patients for a year after episiotomy repair. Compared to the chromic catgut group, women repaired with polyglactin were less likely to have dyspareunia (98 percent versus 13 percent; $\mathrm{RR}=0.59,95$ percent; confidence interval $=0.39$ to $0.91 ; \mathrm{p}=0.02)$ and to fail to resume pain-free intercourse $(8$ percent versus 14 percent; $\mathrm{RR}=0.57,99$ percent confidence interval $=0.39$ to $0.91 ; \mathrm{p}=0.02$ ). Interdependence of confidence.

194 women allocated to polyglycolic suture 106 (55\%) were primipara compared with $79(40 \%)$ of the 197 women allocated to catgut. Although there were no statistically significant differences, parity-adjusted odds ratios (aOR) suggest that compared with women sutured with catgut, women sutured with polyglycolic were less likely to experience perineal pain at day 3 postpartum $(\mathrm{aOR}=0.70$ $95 \%$ confidence interval $[95 \% \mathrm{CI}] 0.46-1.08$ ) but by six months postpartum were somewhat more likely to experience perineal pain $(\mathrm{aOR}=1.77,95 \% \mathrm{CI}=0.57-5.47)$, dyspareunia $(\mathrm{aOR}=1.21[0.62-2.33]$ and require removal of a suture $(\mathrm{aOR}=2.6195 \% \mathrm{CI}=0.59-12.41)^{11}$

As compared to the chromic catgut group, the vicryl rapide group was associated with less pain $(32.5 \%$ versus $57 \%)$ and a less need for analgesia (15.5\% versus 0.5$)$ at $3-5$ days. There was also a significant reduction in the wound indurations, uncomfortable stitches and wound dehiscence $(4 \%$ versus $13.5 \%)$ and a better wound healing $(\mathrm{p}<0.05$ significant) in the vicryl rapide group. ${ }^{12}$

Compared with all above studies, there was statistical reduction in short term pain experienced by patients sutured with vicryl rapide compared to chromic catgut. And all studies proved that there was statistical reduction in requirement of analgesia by vicryl rapide group compared to chromic catgut.

\section{Limitations}

A high frequency of pain and discomfort is felt by women after childbirth and identifying even the relatively small improvements would be important to reduce the morbidity. Such effects may be difficult to distinguish from the biases or the random errors.

\section{CONCLUSION}

Fast absorbing form of polyglactin seems to be effective in reducing some of the morbidity associated with perineal repair following childbirth. There was significant reduction in the short-term pain and the need for analgesia. The incidence of wound dehiscence was markedly reduced.

\section{Funding: No funding sources Conflict of interest: None declared \\ Ethical approval: The study was approved by the Institutional Ethics Committee}

\section{REFERENCES}

1. Perumal D, Selvaraju D. Comparative study of Episiotomy Repair: Absorbable Synthetic Versus Chromic Catgut Suture material. Int J Reprod Contracept Obstet Gynecol. 2017;6:2186-90.

2. Ould F. A Treatise on Midwifery in Three Parts. Dublin: Nelson \& Connor. 1742.

3. DeLee JB. The prophylactic forceps operation. Am J Obstet Gynecol. 1920;1:34-44.

4. Masson F, Bilweis J, Di Lucca D, Trentesaux G, Wrobe N. Interest in a new suture material for 2000 episiotomy repairs: polyglactin 910. Clin Gynecol Obstet. 1988;19-21.

5. Leroux N, Bujold E. Impact of chromic catgut versus polyglactin 910 versus fast-absorbing polyglactin 910 sutures for perineal repair: a randomized, controlled trial. Am J Obstet Gynecol. 2006;194(6):1585-90.

6. Greenberg JA, Lieberman E, Cohen AP, Ecker JL. Randomized comparison of chromic versus fastabsorbing polyglactin 910 for postpartum perineal repair. Obstet Gynecol. 2004;103(6):1308-13.

7. Kettle C, Johanson R. Absorbable synthetic versus catgut suture material for perineal repair. Cochrane database of systematic reviews. 1996;1.

8. Shah PK, Nickalse P, Gourewar V, Dholakia S. A randomized comparative study of polyglactin-910 vs chromic catgut for postpartum episiotomy repair; A pilot study. Obstet Gynaecol. 2001;6(8):465-8.

9. Royal College of Obstetricians and Gynaecologists (RCOG). Method and materials used in perineal repair. London (UK): Royal College of Obstetricians and Gynaecologists (RCOG); 2004 Guidelines. No. 23.

10. Joseph K, Shantha B, Prakash S. Comparative study of episiotomy repair: Absorbable synthetic versus chromic catgut suture material. J Obstet Gynecol India. 2008;58(6):495-9.

11. Upton A, Roberts CL, Ryan M, Faulkner M, Reynolds M, Raynes-Greenow C. A randomised trial, conducted by midwives, of perineal repairs comparing a polyglycolic suture material and chromic catgut. Midwifery. 2002;18(3):223-9.

12. Bharathi A, Reddy DD, Kote GS. A prospective randomized comparative study of vicryl rapide versus 
chromic catgut for episiotomy repair. J Clin Diagn Res. 2013;7(2):326.

13. Kettle C, Dowswell T, Ismail KM. Continuous and interrupted suturing techniques for repair of episiotomy or second-degree tears. Cochrane Database of Systematic Reviews. 2012;11.

14. American College of Obstetricians-Gynecologists. ACOG Practice Bulletin. Episiotomy. Clinical
Management Guidelines for ObstetricianGynecologists. Obstet Gynecol. 2006;107:957.

Cite this article as: Gowda SH, Rakshitha B. Absorbable synthetic versus catgut suture material for episiotomy repair. Int J Reprod Contracept Obstet Gynecol 2021;10:3516-20. 